\title{
Consideraciones sobre la llamada Literatura del Norte en México
}

\section{Notes on the so-called Northern \\ Literature in Mexico}

\author{
Víctor Barrera Enderle \\ Universidad Autónoma de Nuevo León, México \\ vicbarrera@hotmail.com
}

- Resumen - Este ensayo reflexiona en torno a la reciente elaboración de una categoría de clasificación literaria: la «Literatura del Norte». La literatura mexicana reciente ha experimentado una serie de transformaciones profundas. La hegemonía de las industrias culturales ha promovido profundos desplazamientos al interior del campo literario. La antigua centralización cultural se vio desplazada por nuevas formas de ordenación y difusión de la literatura. El Estado, antiguo patrocinador cultural, perdió su lugar protagónico frente a las nuevas editoriales trasnacionales que reorganizaron la cartografía de las letras mexicanas bajo criterios mercadológicos. Al Norte correspondió una narrativa centrada en algunos tópicos: frontera, narcotráfico, migración, desierto, etc. El presente ensayo aborda las diferentes manifestaciones de este proceso.

Palabras clave: Literatura del Norte, literatura mexicana reciente, crítica literaria y cultural, literatura y globalización.

- Abstract - This essay reflects on the recent development of what it seems to be a literary category: «Northern Literature». Recent Mexican literature has undergone a series of profound transformations. The hegemony of cultural industries has produced deep movements into the literary field. New forms of organization and dissemination of literature displaced former cultural centralization. The State, old cultural sponsor, lost its leading role among the new transnational publishers that reorganized the maps of Mexican literature under market logics. In the North, the narrative had to be centered on a few topics: borderland, drug trafficking, migration, desert, etc. This essay discusses the different expressions of this process.

Keywords: Northern Literature, New Mexican Literature, Cultural and Literary Criticism, Literature and Globalization. 
Expongo estas consideraciones desde la «trinchera», desde ese espacio nebuloso que es el norte (¿norte con respecto a qué?). Pienso que debo iniciar con un desplazamiento, con un rodeo: salir un poco del entorno inmediato para tratar de mirar desde afuera (si es que eso es posible) y desbrozar conceptos, pues tengo la impresión de que estamos frente a una malentendido que ha sido difundido e instalado sin ningún tipo de reflexión y que, si no viramos el rumbo, corremos el riesgo de seguir propagándolo infinitamente. El desplazamiento, más que físico, es metafórico: el distanciamiento crítico. ¿De qué hablamos cuando nos referimos a la Literatura del Norte?

Tendríamos que fragmentar la frase en cada una de sus partes: uno es un concepto artístico; el otro, geográfico. Empiezo por el espacio. Norte: ¿qué es?, ¿qué significado ha tenido en México? De entrada, una zona clasificada (desde diversos ángulos: políticos, jurídicos, estéticos, económicos, literarios) con adjetivos determinantes: desértica, desolada, lejana, agreste, fronteriza, extremosa, polvorienta, violenta. Un lugar que se ha definido en oposición a algo exterior: el centro del país, el sur de Estados Unidos. La determinación geográfica impuso, a su vez, un tono exaltado en la confección del relato de la identidad regional. Crecer en el Norte representaba, desde el inicio, un desafío administrativo, porque aquí, en esta zona otrora difusa y hoy transformada por las desventuras de la vida política reciente, en una suerte de trinchera, asediada por disparos y crisis, el discurso burocrático y racional de la España renacentista no se enfrenta a la disimilitud de las culturas nativas, sino ante la ausencia: el vacío de la zona agreste. La empresa era doble: primero domesticar y luego progresar. La idea de la transformación va aparejada con la de gobierno. Gobernar: trucar el vacío por la presencia. La dotación de sentido pasaba por la glorificación de las faenas caseras (la riqueza del subsuelo y la fertilidad de la tierra eran privilegios del sur). Quien podía conducir una casa, podía gobernar una jurisdicción. Uno de los primeros autores norteños, el regiomontano fray Servando Teresa de Mier, al redactar sus Memorias, obligado por el proceso religioso y judicial que le seguía la Inquisición en 1817, destacaba con orgullo la labor de sus ancestros fundadores del Nuevo Reino de León: sembraban y levantaban muros, lo cual significaba, para él, el derecho a ser alguien, un hijo-de-algo. Poblar significaba adelantar la civilización, llevarla hasta los últimos rincones del vasto reino hispánico. La empresa en sí era literaria: una forma práctica y cotidiana de la épica clásica. No hay labor, a su vista, más importante y fundamental que esa. El solar propio es la figura principal de los escudos heráldicos.

La lejanía (el mismo término suponía una toma de distancia) era literal y metafórica. Se estaba lejos del centro y se vivía de espaldas al «mundo ordenado» de donde procedían los modelos de conductas, las leyes y noticias. Las cosas pasaban en otra parte; la Historia con mayúsculas, también.

Entre esas «cosas ajenas» que sucedían en otros lugares estaba la literatura. Al principio se le concibió, en estas regiones, como la expresión de la alta cultura, 
distinción de la que carecíamos (era parte del mobiliario importado de Europa que llegaba tras una larga travesía y permanecía igual, estático, de generación en generación). Modelo de expresión y aspiración intelectual. Nuestros primeros escritores usaron la expresión literaria para nombrar algo más: la identidad, la memoria, los deberes y los proyectos futuros; pero poco la usaron para crear una voz propia. Escribían inventando a sus posibles lectores (no los había y creo que tampoco los hay en la actualidad) y terminaban perdiendo el rumbo ante la ausencia de respuesta. Pero escribieron, dejando una tradición escondida que aún espera la reivindicación crítica para ajustar cuentas, despejar mitos y hacer recuentos.

Debo, antes de continuar, hacer otra digresión, un nuevo rodeo. Considero necesario reflexionar un poco más en el punto de conjunción de los dos conceptos que subyacen a este fenómeno y que se suelen tergiversar (y silenciar) de manera escandalosa. He hablado de espacio y literatura. Hago una unión momentánea. La geografía de las letras. La asociación entre la escritura y su entorno será siempre problemática pero, en cierta manera, ambos factores son inseparables. Evidentemente, los gentilicios literarios sirven más para la clasificación historiográfica, para el ordenamiento crítico (y, en la actualidad, para vender algunos libros) que para determinar a priori las cualidades y «esencias» de autores y obras. Las fronteras geopolíticas no deberían ser, en rigor, una división literaria (sobre todo si estas separan a países con la misma lengua), y ciertamente no lo son para las labores de creación y recepción (al menos hasta hace algunos años): los autores, las autoras, pueden escribir sobre cualquier asunto; y lo mismo para los lectores: la lectura es una forma de eliminar el tiempo y de acortar distancias e idiomas.

Cuando se habla de literaturas nacionales o regionales (incluso urbanas), se debería mentar (al menos así lo pienso) un fenómeno mayor al de la creación, incluso al de la lectura. Me refiero al llamado campo literario, una comunidad mayor, con diversos agentes y una legislación tácita y compleja. Ahí sí es pertinente conjugar geografía y literatura. Ese proceso (histórico, semiótico, cultural) implica la totalidad de géneros (con todas sus ramificaciones posibles), la aceptación y el rechazo sociales, el gusto y el disgusto individual, el conocimiento, la interpretación, la tergiversación y el olvido de todos quienes participan en esa vida literaria.

La asociación entre literatura y espacio implica, sobre todo en el ámbito de la creación, otro problema no menor: la relación con «la realidad». El gentilicio -la determinación espacial- supone, en las interpretaciones más tradicionalistas sobre el fenómeno literario, una relación directa y subordinada con el entorno. Condición y condena para los creadores. Unos de los paradigmas de la modernidad estética (el paradigma se acentúa aún más en la «era postmoderna») fue el quiebre de la referencialidad artística. La fórmula sería así: a mayor evolución, menor «realismo». He aquí algunos de sus síntomas: la abstracción, la fragmentación, el subjetivismo, la experimentación formal más extrema, el reparo sobre el lenguaje. Una buena cantidad de autores y polemistas públicos (pues lejos están de alcanzar el calificativo de 
críticos) suelen asociar realismo con costumbrismo para desdeñarlo olímpicamente. No me interesa hacer aquí una apología del realismo, solo intento redimensionar el problema. Y el problema tiene que ver con la construcción ficcional, sobre todo, en el campo de la narrativa, pero sin dejar de lado a ninguna de las otras manifestaciones literarias. Daré un breve ejemplo de esta «polémica». Mientras buena parte de los discursos postmodernos se sustentan sobre el carácter ficcional (y antirreferencial) de los discursos, algunos críticos metropolitanos, como James Wood (quien ha hecho algo de ruido con su ensayo How Fiction Works), proponen un «regreso» al realismo para desentrañar la «verdad» de nuestra condición. Al menos esa es una de sus propuestas más interesantes (y más peligrosas): la demostración de la vigencia de la estética del realismo en la narrativa del siglo xxi. Varias cosas pueden decirse y deducirse de esta apuesta. Primeramente, el rechazo al ya viejo cliché postmoderno de la antirreferencialidad del lenguaje. Debo aclarar que este retorno al realismo no es inocente ni representa una simple apuesta por la imitación fiel de la realidad (como suele suceder con la llamada Literatura del Norte, pero ese punto lo abordaré más adelante): es más bien una representación de la experiencia (o de la infinidad de ellas) sobre la realidad. Para Wood, y en esto coincido con él, la ficción se ubica en el mundo y trata sobre el mundo (recordé una lejana idea de Alfonso Reyes expuesta en su teoría literaria: el único material posible de la imaginación es la realidad). Este planteamiento no es nuevo, de hecho, el ensayo de Wood me recordó a Walter Besant y su defensa de la ficción (en 1884 la propuso como una de las bellas artes, tratando de dignificar el oficio de novelista), solo que para Wood el arte de la ficción implica una contradicción tal vez insalvable: la literatura es al mismo tiempo un sistema de códigos y convenciones y una forma de verdad, algo que nos afecta y nos cambia de algún modo. Ante el rechazo postmoderno de la condición de sujetos, la eliminación científica (vía la neurociencia) del yo y el afán por la información total y la clasificación de datos de los «realistas histéricos» (la opción postmoderna del realismo, sustentada en los medios de comunicación como la mejor vía para la comprensión del mundo y sus realidades), Wood propone rescatar el añejo radicalismo de las estrategias formales de realismo moderno (la capacidad de observación y acción del narrador, la construcción magistral de personajes, el desafío constante a la forma), es decir, una suerte de retorno metafísico y moral al yo, con todas las implicaciones que ello trae consigo: el restablecimiento de la figura de autor (y de la figura del lector) y el rescate de las múltiples estrategias con que este se enfrenta al desafío formal para contar algo. He apelado a esta digresión sobre el realismo porque creo que la imbricada relación entre literatura y espacio no ha sido considerada (es más: ha sido silenciada) a la hora de hablar de la Literatura del Norte. Ironía de ironías.

¿Por qué? Simple: esta relación múltiple y heterodoxa con la realidad implicaría una reflexión crítica que pudiera mirar el fenómeno de la Literatura del Norte desde dentro, para deslindarla de los elementos externos que solo han conseguido reforzar el cliché y silenciar las discusiones, promoviendo falsas polémicas. Polémicas 
ensambladas desde el ámbito de la publicidad y la farándula del espectáculo y en donde la misma crítica pública (que sostiene la hegemonía de la industrias culturales) recrimina la «monomanía» de los narradores norteños de hablar sobre violencia y narcotráfico, cuando ha sido ella (esa seudo crítica que llena páginas de revistas y adorna los cintillos rojos que engalanan a los nuevos libros) la que ha consolidado esa asociación.

\section{II}

Creo que no necesito remarcar que, para mí, la llamada Literatura del Norte (de nuevo: norte con respecto a qué, o a quiénes), solo cubre una pequeña parte de un fenómeno mayor; y cuando se la menciona con la pomposidad mediática no me siento aludido ni interpelado como lector, ni como crítico, ni como ensayista. Suena, eso sí, a una parafernalia, a un paisaje forzado e idílico, donde los protagonistas repiten (como si estuviesen leyendo un guión cinematográfico) los lugares comunes y las peripecias que otrora padeciesen los grupos y movimientos literarios para abrirse camino en un medio que solía ser cerrado y selectivo. Literatura del Norte es una fórmula, o mejor: una metonimia (la pequeña parte homogénea de un todo heterogéneo), que precisa de varias reformulaciones. Estas tendrían que ver con las nociones de autor, obra y género literario.

Dos formas distintas de notoriedad. En el pasado (un pasado a la vez cercano y remoto: cercano en el tiempo, lejano en cuanto a los cambios culturales) la publicidad de un autor o un título correspondía, en teoría, a un largo y complicado proceso de lectura (y no digo que no intervinieran en él elementos «extraliterarios» como la condición de clase, la hegemonía de género y el manejo de los códigos que sustentaban el canon literario). En la actualidad, y por lo general, la difusión se lleva a cabo de espaldas a los procesos de lectura. No intervienen tanto los factores que antaño afectaban o influían en la constitución del canon, sino que entran nuevos elementos que agilizan y a la vez excluyen a los otros: estrategias publicitarias que simulan y reproducen (en forma de simulacro) las antiguas formas literarias de consolidación: talento, genio individual, personalidad a la vez vanguardista y marginada; y una biografía construida al vapor para resaltar los momentos más dramáticos de un «escritor incomprendido». La irreverencia, el rechazo exagerado por todo lo que huela a nacionalismo cultural trasnochado, el reconocimiento a sus pares (pero solo a aquellos que también han sido bendecidos por la proyección mediática) y la apelación al lugar común: rechazar a todos aquellos que aún creen en la vinculación entre literatura y sociedad. Todos estos aspectos serían constitucionales de la nueva función de autor. El autor moderno había muerto en la academia occidental, nacía ahora el escritor mediático.

Ahora bien, respecto al concepto de obra no necesito traer aquí las consideraciones de Foucault sobre el tema, bastará con definirla como una función cuyas 
significaciones han cambiado en los últimos años. El trueque de terminologías (cambiar obra por texto) no fue gratuito. El texto apela a la relación con otros textos y denuncia su índole discursiva. Esta tendencia semántica implicaba la ponderación de la escritura respecto al acto creativo, en desmedro, aparentemente, de la figura de autor. El texto ganaba autonomía en el ámbito académico, marginando enfoques más amplios que involucraban, entre otras cosas, el contexto y las contradicciones ideológicas e identitarias de sus creadores. Pero en el terreno editorial, el concepto de obra se debilitaba y se mantenía solo como extensión de algo más que garantizaba su factura: el tema o el apellido del autor. La obra se acartonaba como producto de exportación, cumpliendo con las diversas reglamentaciones aduanales (gran ironía: la idílica visión moderna que veía a la literatura como universal se transformaba en la adecuación de lo literario dependiendo de los vaivenes del mercado).

Otra de las transformaciones importantes fue de corte metonímico: la novela como literatura. Los géneros literarios son, bien lo explicó Alfonso Reyes hace mucho tiempo, funciones, pero también expresiones hegemónicas de épocas precisas. Durante la modernidad, la novela se encumbró como el género masivo, como el gran esfuerzo por disputarle los mecanismos de sentido a la realidad. La novela como totalidad fue la gran empresa literaria de buena parte del siglo xx . Al mismo tiempo, la novela se adecuó a las necesidades de venta. El ascenso de la cultura de masas y el aumento de los niveles de alfabetización ayudaron a esta consolidación. Dentro de esta vorágine hubo espacio para la innovación y la reinvención constante del género. Sin embargo, la capacidad para contar y agrupar historias por temas y consolidar personajes arquetípicos se explotó al máximo. Conforme se exploraban nuevas formas y técnicas narrativas, estas iban poco a poco asimilándose hasta establecerse como modelos fijos y legitimadores. El asombro se volvió rutina y, más que búsqueda, se perseguía la novedad.

La reconfiguración de estos tres factores, de acuerdo a los intereses de las nuevas fuerzas vivas que luchan al interior del campo literario, ha contribuido a la llamada hegemonía de la Literatura del Norte. Súbitamente resultó rentable y atractivo configurar un grupo de autores, delimitar ciertos temas y lanzarlos al gran público bajo una orquestada campaña publicitaria que se sustentaba en la combinación y exhibición de todos los elementos que he descrito recientemente: novedad, exploración formal, vanguardia, polémica literaria y renovación (en realidad variación) de la literatura latinoamericana, la cual, en la lectura del ámbito editorial occidental, se estaba petrificando al seguir explotando, hasta el infinito, los réditos (y los residuos) del realismo mágico, tan en boga desde los días del Boom. Y, por cierto, no estoy generalizando, solamente describo la punta del iceberg, la dimensión más visible de un campo literario particular. Debajo de esa capa de oropel, existen obras y escritores interesantes que han quedado «traspapelados» por no «cumplir» con los requisitos necesarios para su difusión a gran escala. Y más aún: dentro de esa dimensión visible, en la punta de ese iceberg hay también escritores que valen la 
pena, y cuyas expresiones creativas y críticas han sabido aprovechar la coyuntura actual para consolidarse.

\section{III}

Una vez delimitado y descrito el problema, me veo en la necesidad de entrar en materia. Creo, sin embargo, que los rodeos que he dado confirman la condición actual de simulacro de la Literatura del Norte.

Si nos quedamos en la dimensión temática, la Literatura del Norte tiene apenas un par de décadas de existencia. Su denominación proviene del reacomodo del campo literario mexicano en la era de la globalización, cuando el Estado perdió su hegemonía como patrocinador cultural y, a su vez, emergieron o se reforzaron las industrias culturales de corte transnacional (y no estoy afirmando que el Estado no cumpla ya una función de auspicio y promoción, sino que ahora lo hace siguiendo la lógica del capitalismo tardío: un despliegue presupuestal que financia ferias del libro, confecciona ediciones vistosas, organiza encuentros de escritores, y, en general, cumple con el protocolo de las políticas culturales en la era del neoliberalismo, pero no con la labor que uno esperaría, esto es, formar lectores críticos que accedan al capital simbólico y se apropien de los bienes culturales). Entonces, las conductas y los desplazamientos cambian. La «literatura latinoamericana» (vista como un todo más o menos homogéneo desde la década del sesenta, cuando adquirió fama y prestigio a nivel internacional) es parcelada y reclasificada según las expectativas de posibles (y fantasmales) lectores peninsulares, lectores que ahora pertenecían a la comunidad europea y asumían, tal vez por primera vez, los tics y manías de consumidores metropolitanos, esperando, ahora, leer lo que desde antes daban por sentado: la diferencia, el exotismo, la confirmación de la peculiaridad regional a través de los residuos del realismo mágico (patéticos best sellers que multiplicaban hasta el hartazgo una serie de lugares comunes).

No es mi deseo sonar como un pesimista extremo, por ello repito que no estoy afirmando que todo el proceso fuera así; sin duda hubo excepciones, escritores que lograron salvar obstáculos extraliterarios y pudieron aprovechar los beneficios de la nueva estructuración del mundo editorial de habla hispana (pienso en Daniel Sada, por ejemplo). Las circunstancias eran propicias para la implantación de nuevas estrategias de difusión. La globalización se veía entonces como un replanteamiento del orden mundial; en lo local, otorgaba la ilusión del anhelado arribo al «banquete de la civilización» (las «señales» eran claras para ellos: las dictaduras sudamericanas se habían acabado, los viejos gobiernos partidistas y nacionalistas cedían ante las nuevas políticas económicas neoliberales, la burocracia se disfrazaba bajo el pulido concepto de la privatización), y la posibilidad para los autores de superar los lastres de las generaciones anteriores (entre ellos, el trillado cliché del realismo mágico: escribir en los noventa representaba, para una buena parte de los noveles 
creadores, fantasear con la idea de la desterritorialización y trocar Macondo por McOndo, por citar un ejemplo ramplón). Borrar los márgenes y soñar con que el mundo es uno y único.

Eso por una parte; por la otra: la expresión de las diferencias regionales surge de este burdo proceso de homogenización. Al lado de la ficción antirreferencial, la literatura de testimonio (que venía desde la década del sesenta, justo cuando la misma noción de lo literario había principiado a transformarse), y, más peculiarmente, la escritura de la diferencia. Esta última contenía la voz de grupos que otrora habían carecido de espacios para hacerse escuchar. Me vienen a la mente algunos nombres emblemáticos, los enuncio al vuelo: Pedro Lemebel, Joaquín Hurtado -que casi nadie cita, por cierto, al hablar de Literatura del Norte-, pero también: Diamela Eltit, Mario Bellatín y otros más.

En este proceso literario, el norte de México fue visto, desde inicio de la década del noventa, como el «laboratorio de la postmodernidad» (en palabras de Néstor García Canclini), un lugar donde se agigantaban los fenómenos, como si fuesen colocados en un portaobjetos, y se los podía apreciar en toda su diversidad través de lentes de diversos enfoques. Estaban la migración, esa diáspora del Tercer al Primer Mundo (que tanto anuncian los profetas de la postmodernidad), la heterogeneidad cultural, la desigualdad (tanto de raza como de género), la frontera como metáfora y a la vez como escenificación del espacio marginal, la ausencia del Estado y el imperio del mercado (con las maquiladoras como ejemplo supremo), el desierto como metáfora de la ausencia de significación, las ciudades norteñas como espacios marginales que ofrecen la fantasía del bienestar occidental y muy pronto enseñan sus verdaderas fauces (Ciudad Juárez sería el modelo emblemático). El norte mexicano es el fin de viaje de la literatura latinoamericana moderna (como prueba estaría la narrativa de Roberto Bolaño).

\section{IV}

La Literatura del Norte se ha convertido, así, en una convención que implica, de manera implícita, un corte temporal y un eje temático. El aspecto temporal se reduce, como he sugerido, a las últimas dos décadas (bien podríamos marcar como punto de partida 1990), cuando se instalaron en el campo literario mexicano los mecanismos de producción y distribución propios de la era de la globalización. ¿Qué quiero decir con esto? Me refiero al momento en que las formas modernas de publicar y distribuir obras literarias (que venían reorganizándose desde que Barcelona se consolidó como la capital del mundo editorial de habla hispana en los años sesenta y setenta), basadas, como ya he mencionado a lo largo de estas páginas, en la figura de autor y en la supuesta calidad de la obra, es decir, en criterios de lectura, son sustituidas por procesos más dinámicos e inmediatos que dejan olímpicamente de lado la "opinión del lector» y tergiversan los juicios críticos para garantizar que los ejemplares se vendan. No me interesa idealizar el pasado, y no voy a caer en el lugar 
común de ponderar los días pretéritos como mejores, denostando el presente, pero antes, al menos en teoría, las obras daban prestigio a las editoriales y a los premios; ahora suele ser a la inversa. Para el momento en que un libro es distribuido ya está clasificado y adjunto a la historia literaria. Incluso da la impresión de haber sido leído previamente de manera unívoca y autoritaria, y lo que nos entregan es solo una posible lectura de la obra. Y para evitar cualquier tipo de disidencia se cierran o silencian previamente los pocos espacios para la discusión crítica. Visto así, nuestra única opción como lectores parece ser la aceptación (la resignación), pues el tema no está puesto a discusión. Si no estamos de acuerdo, peor para nosotros, pues, en su perspectiva, estamos corriendo el riesgo de quedar fuera del juego, y de ser vistos como lectores anacrónicos y resentidos.

Recuerdo, apelando a mi memoria de lector, el surgimiento de este supuesto nuevo boom literario a finales del siglo xx y principios del xxI. Cuando surgió el fenómeno editorial de la literatura del Norte, el «paradigma» cambió estrepitosamente. Muchos de los críticos públicos, convertidos ahora y casi por arte de magia en historiadores de la literatura, hablaban de un nuevo corte, del surgimiento de una nueva era literaria. ¡Por fin algo nuevo!, exclamaban en los titulares de sus notas. La moda era hablar de la frontera, apelar a la cultura del narco, a la geografía del desierto. Todo el mundo comentaba el surgimiento de este fenómeno: se orquestaban congresos (a mí me tocó participar en varios, y en todos sentía que asistía a la representación de una obra teatral con un gran decorado de fondo: "¿de qué Norte están hablando?», pensaba al escuchar las conferencias magistrales, casi todas, por cierto, dictadas por escritores famosos); se dirigían tesis que proponían insólitas hipótesis sobre este nuevo género literario; y todos parecían muy felices, pues, en un instante, la dinámica se había transformado: el añejo centralismo cultural aparecía debilitado ante el impulso vigoroso de los nuevos escritores norteños (en realidad, incluso este fenómeno era otra manifestación, esta vez renovada y muy bien maquillada, de ese centralismo). La ficción se presentaba como referencia histórica. Y uno no podía evitar sentir lo forzado del proceso, algo no encajaba. El tinglado se venía abajo apenas se observaba el fenómeno con atención. Las reseñas de los diarios y revistas se sincronizaban y ponderaban y aplaudían a las mismas obras y a los mismos recursos narrativos. Y, cuando leíamos esas obras impulsados por tanto entusiasmo, la decepción era mayor. Al final, no pasaba nada. Y la prueba es que, al paso de unos pocos años, la mayoría de esos títulos tan bien reseñados han pasado al olvido.

Muchos de mis amigos escritores (que solían tener un amplio repertorio temático, el cual iba desde el intimismo más refinado hasta la ciencia ficción) padecieron transformaciones parecidas. De pronto se «descubrieron» redactando historias truculentas, infladas con todos los ingredientes antes mencionados. Al cuestionarlos por tan repentino cambio, me confesaban: «queremos que nos publiquen». Tal era la consigna. El Norte de México había dejado de ser un espacio en la dilatada geo- 
grafía nacional y ahora se convertía en un género literario. Uno de los argumentos defensivos que más escuchaba (el que repetían públicamente con mayor frecuencia, sin duda) se basaba -otra de las grandes ironías de la vida- en el compromiso del escritor, esto es, en la necesidad de «denunciar una realidad de la que no hablan los medios» (¡pero si de algo hablan los medios ahora es de la violencia provocada en la región por la guerra contra el narcotráfico!). «Tenemos que dar cuenta de lo que pasa», exclamaban con fuerza y decisión. Y sin embargo me pregunto: ¿es tan así el problema? Veamos. El narcotráfico ha existido en la región al menos desde hace más de cincuenta años; novelas y cuentos con ese tema se han escrito desde la lejana década del sesenta. ¿Por qué, de pronto, era tan urgente abordar dicho asunto? ¿Y por qué presentar dicho abordaje como nuevo, como si nadie lo hubiera hecho antes? Mi primera respuesta sería, sin dudarlo mucho: por la demanda editorial.

El proceso apela a la desmemoria, incluso contribuye a ella. Estas series de novelas, abrigadas con reseñas halagüeñas y con ensayos propagandísticos, eran presentadas como la gran novedad, como el gran hallazgo. Y, de nueva cuenta, uno, como lector, se quedaba impresionado por la maniobra tan burda, por la inversión del proceso. Es la demanda editorial la que influye en el procedimiento creativo, y, una vez que se ha llevado a cabo la creación bajo este tipo de presión mercantil y la obra se ha publicado porque cumple con todos los requisitos para su distribución, la campaña editorial la presenta (a la obra) como una creación heterodoxa que viene a romper con todo lo establecido. ¡Parece cosa de locos!

$\mathrm{Y}$ es esa falta de espontaneidad, ese ensamblado tan forzado y tan frágil, lo que asombra, en la peor acepción del término. La construcción discursiva del Norte terminó por convertirse en la principal referencia para los escritores norteños. Para demostrar la fuerza de esta demanda editorial podría citar como ejemplo el caso de un conocido autor español (creador de varios éxitos de ventas) que, en plena apoteosis de la moda de la literatura del Norte, escribió su propia novela de narcos. En la era de la hegemonía de las industrias cultura, nada es casualidad. Y la lista de ejemplos parecidos podría seguir de manera infinita, pero creo que con lo que he mencionado aquí basta para dar una idea clara del fenómeno.

El eje temático tiene que ver con una sola interpretación de la realidad, con la preponderancia del medio sobre las acciones. El Norte como la frontera de la cultura y de la civilización. Estamos ante un nuevo esfuerzo por dotar de sentido y significación, un supuesto espacio vacío. Y el problema es que esta dotación de sentido se da con elementos extraliterarios (como lo es la confección de la demanda editorial). Todo se desborda: el narcotráfico como la manifestación más nítida del capitalismo salvaje, el desierto como el escenario idóneo para las pasiones más desmedidas. La narrativa no puede, ante tal expectativa, escapar de la linealidad más llana (es el realismo literario que rechaza James Wood por su carácter ancilar, dependiente; un realismo que no cuestiona, que no reinventa, sino que afirma «reproducir» la realidad sin aportar una experiencia que se pueda transmitir sobre ella, 
sobre esa supuesta realidad). El engranaje editorial espera que se cumplan las formas y, si acaso deja espacio para la experimentación, se asegura de que los límites no se crucen. Las mismas variaciones terminan por confirmar la fórmula y consolidar el género. La tácita imposición tiene como gancho la promesa de la profesionalización. Ser escritor profesional significaría aquí tener un público cautivo, firmar contratos editoriales, comprometerse a la difusión de las obras, en pocas palabras, la ilusión de ser un escritor del Primer Mundo, valorado como una figura pública respetable. La configuración de la Literatura del Norte ha otorgado, por primera vez, la promesa de la autonomía literaria en la región. Para tal efecto ha instalado una serie de estrategias y procedimientos que intentan consolidar la actividad literaria en el ámbito social (muchas de esas estrategias siguen siendo financiadas por el Estado, pues el mercado solo ofrece la ilusión de la profesionalización pero nunca garantiza la satisfacción y la igualdad para todos).

Ahora nos encontramos inmersos en esa circunstancia, y eso ha aletargado nuestra reflexión crítica. Comenzamos a aceptar, sin cuestionar, la definición del fenómeno desde la posición de simples espectadores. Gran ironía: la globalización nos vendió la ilusión de la descentralización cultural lo que finalmente ha reforzado el centralismo. Durante la formación del Estado la estrategia principal fue la homogeneización; durante la globalización la estrategia es la ponderación de la diversidad. Al final el resultado es el mismo: la ausencia de un diálogo entre iguales. La Literatura del Norte, como parte de este fenómeno, se está convirtiendo en una categoría fija, en un pesado obstáculo que puede limitar y distorsionar nuestro derecho a la representación estética.

La única manera de eliminar esa metonimia incómoda y de comenzar a mirar el fenómeno en su complejidad es planteando nuevas estrategias de lectura: asomarnos a otros géneros (la poesía ha producido en la región voces muy interesantes) y dialogar críticamente con ello. Si se habla con tanto afán de la Literatura del Norte, es hora de que también comencemos a hablar de Lectores del Norte.

Recepción: Abril 2012 